\title{
Individual and sequential effects of stirring, smoothing, and cooling on the rheological properties of nonfat yogurts stirred with a technical scale unit
}

\author{
V. Guénard-Lampron, ${ }^{*} \dagger \ddagger$ D. St-Gelais, ${ }^{*} † \ddagger ~ S . ~ V i l l e n e u v e, \dagger \ddagger$ and Sylvie L. Turgeon ${ }^{*}{ }^{1}$ \\ *Dairy Science and Technology Research Centre (STELA), and \\ †Institute of Nutrition and Functional Foods (INAF), Université Laval, Quebec City, QC G1V 0A6, Canada \\ $\ddagger$ St-Hyacinthe Research and Development Centre, Agriculture and Agri-Food Canada, 3600 Casavant Boulevard West, St-Hyacinthe, \\ Qc, J2S 8E3, Canada
}

\section{ABSTRACT}

Few studies have considered the impact of unit operations during stirred yogurt manufacture because their operational sequence is difficult to replicate at the laboratory scale. The aim of this study was to investigate the individual and sequential effects of stirring in the yogurt vat, smoothing, and cooling on the rheological properties of yogurts, using a technical scale unit simulating some industrial conditions. The yogurts were prepared from a milk mixture that was standardized to contain $14 \%$ total solids, $0 \%$ fat, and $4 \%$ protein, and then homogenized, heated $\left(94.5^{\circ} \mathrm{C}, 5 \mathrm{~min}\right)$, and inoculated at $41^{\circ} \mathrm{C}$ with the same thermophilic lactic starter. The operating parameters under investigation were 2 stirring durations in the yogurt vat (5 or $10 \mathrm{~min}), 2$ cooling systems (plate or tubular heat exchanger), and 2 smoothing temperatures $\left(38^{\circ} \mathrm{C}\right.$ for smoothing before cooling; $20^{\circ} \mathrm{C}$ for smoothing after cooling). Sampling valves were installed at critical points on the technical scale unit so that the effect of each operation on the properties of stirred yogurt could be quantified individually. Syneresis, apparent viscosity, firmness, and consistency were analyzed after $1 \mathrm{~d}$ of storage at $4^{\circ} \mathrm{C}$. In general, as the yogurts moved through the technical scale unit, the properties of the yogurts (evaluated after $1 \mathrm{~d}$ ) changed: viscosity increased but syneresis, firmness, and consistency decreased. The individual effects of the operations showed that smoothing and cooling, compared with stirring duration, made the greatest contribution in terms of modifying yogurt properties. The stirring parameters (5 or $10 \mathrm{~min}$ ) had similar effects on the yogurts. The use of a plate heat exchanger promoted a decrease in syneresis, whereas a tubular heat exchanger had a greater effect in terms of

Received February 9, 2018.

Accepted July 9, 2018.

${ }^{1}$ Corresponding author: sylvie.turgeon@fsaa.ulaval.ca increasing firmness and consistency. The type of cooling system had no effect on stirred yogurt viscosity. Smoothing at $38^{\circ} \mathrm{C}$ had a greater effect on the increase in firmness, whereas smoothing at $20^{\circ} \mathrm{C}$ contributed more to a decrease in syneresis and increases in viscosity and consistency. This study confirms that each unit operation has a defined effect on the rheological properties of a nonfat stirred yogurt, which also depends on the operation sequence.

Key words: stirred yogurt, technical scale unit, rheological property

\section{INTRODUCTION}

Between 1998 and 2017, Canadian yogurt consumption per capita increased by $280 \%$ (Canadian Dairy Information Centre, 2018). Among the yogurts produced, the top-selling types are set yogurt and stirred yogurt. Whereas set yogurt undergoes fermentation directly in the retail container, the fermentation of stirred yogurt occurs in the yogurt vat, and the stirring, pumping, smoothing, and cooling operations are performed before the yogurt is packed into retail containers (Tamine and Robinson, 1999).

Each of these operations induces mechanical stress that breaks up the protein network into gel particles (Arshad et al., 1993; Zoon, 2003; Renan et al., 2009). This breaking of the acidified gel may lead to texture defects, such as major losses of firmness and viscosity, or to the expulsion of whey (Sodini et al., 2004). The industry can address such texture problems by adding fat or texturizers or by using an exopolysaccharideproducing starter (Hess et al., 1997; Lucey, 2004; Sodini et al., 2004). However, excessive use of texturizers or exopolysaccharide can have a negative effect on the sensory properties (flavor) of the product or even stabilize the gel too much, resulting in a rubbery texture (Hess et al., 1997; Trachoo, 2002; Lucey, 2004; Teles and Flôres, 2007). To control rheological properties of 
Table 1. Composition of the ingredients used to standardize yogurt milk

\begin{tabular}{|c|c|c|c|c|c|c|}
\hline Ingredient $^{1}$ & \multicolumn{6}{|c|}{ Component (\%) } \\
\hline$\overline{\text { Skim milk }^{2}}$ & $3.0 \pm 0.1$ & $0.4 \pm 0.1$ & $2.0 \pm 0.1$ & $0.6 \pm 0.02$ & $8.4 \pm 0.2$ & $0.15 \pm 0.05$ \\
\hline WPC34 & 34.1 & 3.4 & 0.0 & 30.7 & 97.4 & 0.01 \\
\hline Lactose & 0.0 & 0.0 & 0.0 & 0.0 & 98.9 & 0.0 \\
\hline Starter & 4.4 & 0.09 & 3.4 & 0.9 & 11.7 & 0.001 \\
\hline
\end{tabular}

${ }^{1} \mathrm{SMP}=$ low-heat skim milk powder; WPC34 = 34\% whey protein concentrate.

${ }^{2}$ The values for skim milk are the averages \pm SEM of the values measured with an FT120 infrared analyzer (Foss North America, Eden Prairie, $\mathrm{MN}$ ) in the milk used for all batches.

yogurts to meet consumer expectations, it is essential to understand the effect of production operations. For example, stirring aims to make the gel uniform, but stirring length and intensity are critical (the limits are not clear) to maintain yogurt viscosity (Abu-Jdayil et al., 2013). Pumping was shown to circulate the yogurt through the pipes without having any major effect on the yogurt's properties (Chandan and O'Rell, 2006). However, the type of pump used is critical; a highrotation pump (centrifugal pump) greatly decreases yogurt viscosity, whereas a low-rotation pump (positive pump) that induces low mechanical stress could maintain the structural properties of the gel (Senge and Blochwitz, 2009). The smoothing step reduces the presence of lumps perceptible by the consumer (size $>150$ $\mu \mathrm{m}$; Lucey, 2004; Cayot et al., 2008; Mokoonlall et al., 2016). The smoothing temperature may also be critical but has been poorly investigated. It is not recommended to perform smoothing on cold yogurt because the high-pressure pumping required to circulate the yogurt creates a high mechanical stress that negatively affects its rheological properties (Tamine and Robinson, 1999). However, smoothing performed at a higher temperature or just after fermentation could damage the structure of the gel, which is still fragile at that point (Lucey, 2004). Rapid cooling was shown to cause the expulsion of whey (Chandan and O'Rell, 2006). The type of cooling system used (plate or tubular heat exchanger) can also apply mechanical stress to the gel, particularly when a plate heat exchanger is used, resulting in reduced viscosity and firmness (Sanchez et al., 1994; Maingonnat et al., 2005; Senge and Blochwitz, 2009).

The literature on the effects of stirring, smoothing, and cooling operations is incomplete. Studies investigating the effects of yogurt stirring steps were performed mainly at the laboratory scale and did not include the complete sequence of operations. Furthermore, most studies used yogurts containing fat (Tamine and Robinson, 1999, 2007; Senge and Blochwitz, 2009; Mokoonlall et al., 2016), which may be more resistant to mechani- cal stresses. The yogurt industry therefore needs more data on the production of stirred yogurts, including the combined effect of stirring, pumping, smoothing, and cooling on the rheological and physical properties of nonfat stirred yogurt. The aim of this study was to investigate, using a technical scale unit, the individual and sequential effects of 2 stirring durations, 2 smoothing temperatures, and 2 cooling systems on syneresis, apparent viscosity, firmness, and consistency of nonfat stirred yogurts.

\section{MATERIALS AND METHODS}

\section{Milk Ingredients}

Pasteurized skim milk (Laiterie Chalifoux Inc., SorelTracy, QC, Canada) was used to produce the nonfat yogurts. Low-heat skim milk powder (Quadra Chimie Ltée., Vaudreuil-Dorion, QC, Canada), whey protein concentrate (Agropur, St-Hyacinthe, QC, Canada), and lactose (Quadra Chimie Ltée.) were used to standardize the composition of yogurt milk. The composition of each ingredient is presented in Table 1.

\section{Bacterial Strains, Starter, and Culture Medium}

A non-ropy freeze-dried commercial culture containing a mixture of the lactic acid bacteria Streptococcus thermophilus and Lactobacillus delbrueckii ssp. bulgaricus (Yo-Dolce; Biena, St-Hyacinthe, QC, Canada) was used to prepare the starter. The composition of the starter is presented in Table 1. On the day before yogurt production, the starter was prepared using reconstituted milk that was made from $12 \mathrm{~g}$ of skim milk powder per $100 \mathrm{~g}$ of Millipore water (Milli-Q Water System, Fisher Scientific, Nepean, ON, Canada) and agitated for $10 \mathrm{~min}$ on a hot plate at $40^{\circ} \mathrm{C}$. The reconstituted milk was sterilized at $110^{\circ} \mathrm{C}$ for 6 min and then cooled to $41^{\circ} \mathrm{C}$, inoculated with the bacterial culture at a rate of $1 \mathrm{~g} / \mathrm{L}$, and incubated at $41^{\circ} \mathrm{C}$ until the $\mathrm{pH}$ reached 
4.7. On average, incubation time was $311 \pm 6 \mathrm{~min}$ for all the yogurt batches. Once the target $\mathrm{pH}$ was reached, the starter was stored at $4^{\circ} \mathrm{C}$ until yogurt production. A sample was taken to determine the populations of $S$. thermophilus and L. bulgaricus.

\section{Yogurt Production}

Skim milk was standardized to $0 \%$ fat, $4 \%$ total protein (with a casein-to-whey-protein ratio of 2.8), and $14 \%$ TS by adding the various ingredients presented in Table 1. Skim milk powder was added mainly to adjust the casein content, and whey protein concentrate was added to adjust the whey protein content. Lactose was added to standardize the yogurt milk at $14 \%$ TS to minimize the variation in rheological properties that could be induced by different milk solid contents.

The yogurt milk was rehydrated for 5 min by using a pump (FM-O/115; Alfa-Laval, Lund, Sweden) in a closed-loop system and was then transferred into the supply yogurt vat for the pasteurizer (plate pasteurizer, $2000 \mathrm{~L} / \mathrm{h}$; Alfa Laval) and preheated to $60^{\circ} \mathrm{C}$ by circulation of steam-heated water. Afterward, the milk mixture was homogenized in 2 stages, the first at $13.80 \mathrm{MPa}$ and the second at $3.45 \mathrm{MPa}$ (homogenizer, 500-2,000 L/h; Alfa Laval). The homogenized milk was then heated to $94.5^{\circ} \mathrm{C}$ for $5 \mathrm{~min}$ in another heating section of the plate pasteurizer and cooled to $40^{\circ} \mathrm{C}$ when the yogurt milk passed through the regeneration section. To prevent dilution of the yogurt milk by residual water, a conductivity meter (Henkel, LM03; Alfa Laval) was installed at the outlet of the pasteurization system. When the conductivity meter reading was $>90 \mathrm{mS} /$ $\mathrm{cm}$ (corresponding to the conductivity of nonfat milk at $40^{\circ} \mathrm{C}$ ), the yogurt milk was poured into three $30-\mathrm{L}$ yogurt vats, each with a cone-shaped spout. The yogurt vat had been treated beforehand with $12 \mathrm{ppm}$ of chlorine and rinsed thoroughly with water. The yogurt vats were placed into a yogurt incubator (Magelis; Schneider Electric, Brossard, QC, Canada) at $40^{\circ} \mathrm{C}$. Every hour, each yogurt vat was inoculated with active starter at a rate of $1.5 \%(\mathrm{vol} / \mathrm{vol})$ and its composition was considered in the standardization of yogurt milk (Table 1). The $\mathrm{pH}$ was measured (portable $\mathrm{pH}$ meter, model HI 99161; Hanna Instruments, Laval, QC, Canada) every hour, and the yogurt vats were taken out of the incubator when the $\mathrm{pH}$ reached 4.7. The acidification curve pattern was similar for all fermentations and the incubation time averaged $231 \pm 10 \mathrm{~min}$.

\section{Technical Scale Unit}

A technical scale unit was developed to simulate industrial stirring conditions and understand how the various operations affect the rheological properties of stirred yogurt (Figure 1). The stirring operation in the yogurt vat was performed using a stainless steel helical blade mixer (Penta KB power drive, NEMA-4X/IP-65; Baldor, Fort Smith, AR; Tamine and Robinson, 1999) designed specifically for a 30-L cone-shaped spout yogurt vat $(50.8 \times 40.6 \mathrm{~cm})$. In addition, removable baffles $(47.0 \times 2.5 \mathrm{~cm})$, installed at a $45^{\circ}$ angle to the direction of flow to thoroughly break up the gel, were operated only during the first $30 \mathrm{~s}$ of mixing. A positive displacement pump (Seco DANA, model 210; Bronco Industries, Delta, BC, Canada) used to circulate the yogurt was monitored using a straight, cylindrical pipes $(3.4 \mathrm{~cm}$ in diameter). A digital pressure gauge (Distribution Qualtech, St-Hyacinthe, QC, Canada) installed just downstream of the pump was used to measure the pressure in the pipes. A bidirectional valve was also installed to direct the yogurt to either a $4.3-\mathrm{m}$ tubular heat exchanger (THX; PG7757/84, Sepak Industries Pty Ltd., Sydney, Australia) or a 3.4-L plate heat exchanger (PHX; type A3-HBM, Alfa Laval). The 2 heat exchangers were connected in a counterflow configuration to a cold water system to lower the temperature of the yogurt from $40^{\circ} \mathrm{C}$ to $20^{\circ} \mathrm{C}$. The temperature data logger (OM-DAQPRO- 5300; Omega Engineering, Stamford, CT) connected to thermocouples (Type K) was installed in the yogurt pipe in front of and after the cooling system.

Preliminary testing showed that the cooling water should be at $20^{\circ} \mathrm{C}$ for the PHX and $14^{\circ} \mathrm{C}$ for the THX so that the stirred yogurt comes out of the technical scale unit at $20^{\circ} \mathrm{C}$. The smoothing operation was done using a filter nozzle, an efficient and inexpensive tool. Smoothing was performed at $38^{\circ} \mathrm{C}$ or $20^{\circ} \mathrm{C}$ with a 425 $\mu \mathrm{m}$ filter nozzle (\#40 sieve, surface area of $31 \mathrm{~cm}^{2}$ ) installed upstream $\left(38^{\circ} \mathrm{C}\right)$ or downstream $\left(20^{\circ} \mathrm{C}\right)$ of the cooling system. Pre-smoothing was performed with a 1.4-mm filter nozzle (\#14 sieve, surface area of $37 \mathrm{~cm}^{2}$ ) positioned upstream of the cooling system when the smoothing operation was performed at $20^{\circ} \mathrm{C}$. The filter was cleaned between the passage of each production of yogurt to prevent blocking or clogging. Sampling valves were installed at critical points on the technical scale unit to allow quantification of the individual effect of each operation on the rheological properties of the yogurts (Figure 1). Valves were placed at a $45^{\circ}$ angle to minimize the mechanical stress during sampling and were opened only once to fill containers.

\section{Operation of the Technical Scale Unit and Collection of Yogurt Samples}

The technical scale unit was used in 1 of 2 configurations, depending on whether the smoothing filter nozzle 
was placed upstream or downstream of the cooling system (Figure 1). For both configurations, the first 2 samples were collected in the same way. The first sample was completely collected when the $\mathrm{pH}$ reached 4.7 , with a 2-L sample taken downstream of the fermentation yogurt vat (YV). This 2-L sample was distributed into $175-\mathrm{mL}$ containers to allow analysis of the gel properties before the yogurt was stirred (sample collection point 1, Figure 1). The yogurt vat was then connected to the technical scale unit and the mixer and baffles were placed into the yogurt vat for stirring at a mixing speed of $30 \mathrm{rpm}$ for the desired time: $5 \mathrm{~min}$ (St5) or $10 \mathrm{~min}$ (St10). After $30 \mathrm{~s}$, the baffles were removed, and after 5 or 10 min of stirring, the mixing speed was reduced to and maintained at $15 \mathrm{rpm}$. After the stirring step, the yogurt temperature averaged 37.8 $\pm 0.1^{\circ} \mathrm{C}$. The yogurt was then pumped into the piping of the technical scale unit. To determine the effect of 5 or $10 \mathrm{~min}$ of stirring in the yogurt vat, a second sample $(2 \mathrm{~L})$ was collected from a valve installed just in front of the pump (sample collection point 2, Figure 1). After that, 3 other samples were taken for the different configurations, as described below.

Configuration 1. In the sequence of operations for configuration 1 (Figure 1), smoothing occurred before the cooling system and was therefore performed at a temperature of about $38^{\circ} \mathrm{C}$ (SM38). Yogurt samples were collected directly into 175 -mL containers through valves installed upstream and downstream of the smoothing filter nozzle (sample collection points 3 and 4). These samples were designed to differentiate the effect of pumping (PU) and smoothing (SM38) before cooling (CO). The yogurt was subsequently directed either to the PHX or the THX for cooling to $20^{\circ} \mathrm{C}$, and stirred yogurt samples were collected (sample collection point 5).

Configuration 2. The sequence of operations for configuration 2 (Figure 1) consisted of pre-smoothing through a filter nozzle, cooling, and then smoothing at $20^{\circ} \mathrm{C}$ (SM20). Yogurt samples were therefore taken only downstream of the pre-smoothing filter nozzle (sample collection point 3) but upstream of the cooling system, to assess the combined effect of pumping and pre-smoothing (PU+PSM). The yogurt was then directed into 1 of the 2 cooling systems (PHX or THX), and samples were taken through a valve installed just after the cooling system but in front of the smoothing nozzle (sample collection point 4), to isolate the effect of CO. After smoothing, stirred yogurt samples were taken (sample collection point 5) to isolate the effect of

\section{Technical scale unit}

\section{Sample \\ (O)}

Location

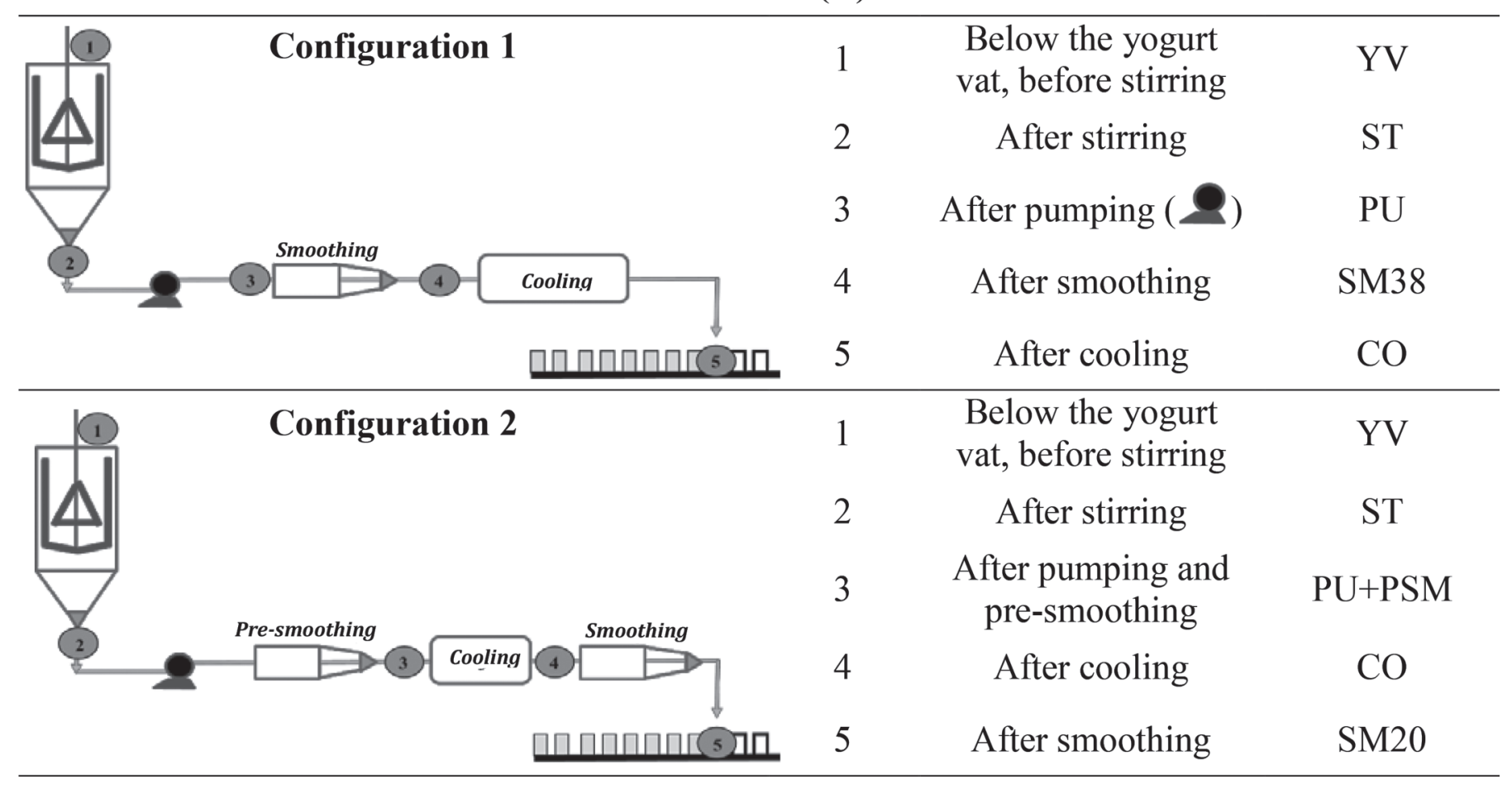

Figure 1. Description of the 5 sample collection points in configurations 1 and 2 of the technical scale unit. 
smoothing at $20^{\circ} \mathrm{C}(\mathrm{SM} 20)$. All yogurt samples taken from both configurations were immediately stored in a cold room at $4^{\circ} \mathrm{C}$ for $1 \mathrm{~d}$ to determine the individual and sequential effects of the operations.

The technical scale unit was therefore used to investigate 2 stirring durations (St5 and St10), 2 smoothing temperatures (SM38 and SM20), and 2 cooling systems (PHX and THX), resulting in 8 different sequential combinations.

\section{Analysis of Yogurts}

The yogurt samples taken at points 1 to 4 (Figure 1 , configurations 1 and 2) were used for the following analyses after $1 \mathrm{~d}$ of storage at $4^{\circ} \mathrm{C}$ : syneresis, firmness, apparent viscosity, and Bostwick consistency. The yogurt samples taken at point 5 (Figure 1, configurations 1 and 2) were used to perform the analyses described above and to determine changes in $\mathrm{pH}$, lactic acid bacteria count, and flow through a Posthumus funnel after $1 \mathrm{~d}$ of storage at $4^{\circ} \mathrm{C}$.

Analytical Methods. For every day of yogurt production, fresh skim milk was analyzed with an FT120 infrared analyzer (Foss North America, Eden Prairie, $\mathrm{MN}$ ) to determine the concentrations of total N, caseins, whey proteins, fat, and TS. For ingredients and yogurt milks, fat contents were determined by the official Röse-Gottlieb method (AOAC International, 2000; method 989.05) with a Mojonnier extraction flask; TS contents by an official standard method (AOAC, 1990; method 990.20); and total N, NPN, and noncasein N contents by a macro-Kjeldahl method (AOAC International, 2000; method 991.20, Tecator Kjeltec, Höganäs, Sweden). Nitrogen components were prepared as described by Gentès et al. (2013). The composition of yogurt milks was determined before heat treatment. The $\mathrm{pH}$ of the yogurts were measured during storage using official standard methods (AOAC International, 2000; method 981.12).

Microbiological Counts. The samples were prepared using an official method (ISO-IDF, 2003; ISO 7889/IDF 117). For counts, M17 agar medium supplemented with lactose at $0.5 \%$ (Difco, Sparks, MD) was used for streptococci, and MRS (Difco) acidified with glacial acetic acid (99.7\%; Laboratoire MAT, Montreal, QC, Canada) at $0.2 \%$ (vol/vol) for lactobacilli. The plates were incubated under anaerobic conditions at $37^{\circ} \mathrm{C}$ for $48 \mathrm{~h}$.

Physical and Rheological Properties. Syneresis was evaluated using a centrifugation method (Everett and McLeod, 2005), which involved collecting $25 \mathrm{~g}$ of yogurt with a yogurt sampler and placing the sample in a 50-mL tube (Sarstedt, Saint-Léonard, QC, Canada).
Centrifugation (Sorvall ST40R centrifuge, TX-750 rotor; Thermo Scientific, ON, Canada) was performed at $210 \times g$ for $20 \mathrm{~min}$ at $4^{\circ} \mathrm{C}$, and the supernatant (i.e., whey) was removed by inversion and weighed. Duplicates were performed for each yogurt. Syneresis was calculated using equation [1], as follows:

$$
\text { Syneresis }(\%)=\frac{\text { Supernatant collected }(\mathrm{g})}{\text { Yogurt analyzed }(25 \mathrm{~g})} \times 100 \text {. }
$$

Firmness was measured using the method of Hess et al. (1997) using a TA-XT2 texture analyzer (Texture Technologies Corporation, Scarsdale, NY) to determine the penetration force of a $25-\times 35-\mathrm{mm}$ cylindrical probe with a $5-\mathrm{kg}$ load cell (Eq. [2]). The penetration speed was $1.0 \mathrm{~mm} / \mathrm{s}$, and the penetration depth was $10 \mathrm{~mm}$. The value represents the mean of 5 measurements performed at $4^{\circ} \mathrm{C}$ for each yogurt:

$$
\text { Firmness }\left(\mathrm{N} / \mathrm{m}^{2}\right)=\frac{\text { Maximum penetration force }(\mathrm{N})}{\text { Area of probe }\left(4.91 \times 10^{-4} \mathrm{~m}^{2}\right)} \text {. }
$$

Apparent viscosity was determined by analysis with a rheometer (Physica MCR301 rheometer; Anton Paar GmbH, Ostfildern, Germany) using a concentric cylinder measuring system (model CC-27 SN23489, $26.66 \mathrm{~mm}$ diameter; Anton Paar $\mathrm{GmbH}$ ). Using a yogurt sampler, $21 \mathrm{~g}$ of yogurt was carefully collected, weighed, and placed in the concentric cylinder of the rheometer (model CC-27, $28.92 \mathrm{~mm}$ diameter; Anton Paar $\mathrm{GmbH}$ ). The samples were maintained at $4^{\circ} \mathrm{C}$ by the rheometer's Peltier temperature control system (model C-PTD200; Anton Paar GmbH). The samples were allowed to stand for 5 min before the analyses began; then, 20 apparent viscosity values were measured and recorded (Physica RheoPlus software; Anton Paar $\mathrm{GmbH}$ ) at intervals of $5 \mathrm{~s}^{-1}$ to create a range of shear rates from 0 to $100 \mathrm{~s}^{-1}$. Apparent viscosity at a shear rate of $10.5 \mathrm{~s}^{-1}$ was used for comparison. These analyses were conducted only once at $4^{\circ} \mathrm{C}$ for each yogurt.

Consistency was determined with a Bostwick consistometer (CSC Scientific Co., Fisher Scientific, Nepean, ON, Canada) to evaluate resistance to flow of the yogurts by the ASTM standard method (ASTM, 2013; Standard F1080-93). Flow on an inclined plane is caused by the effect of the gravitational force on the product (McCarthy and McCarthy, 2009). The flow distance depends on the viscosity but also on the elastic properties and adherence of the product to the surface of the consistometer (Monnet et al., 2008). The springloaded gate was first closed so that the reservoir could 
be filled to the upper limit $(75 \mathrm{~mL})$, and then the gate was opened, instantaneously releasing the yogurt. The distance (in $\mathrm{cm}$ ) that the yogurts traveled after $30 \mathrm{~s}$ was recorded. Triplicates were performed for each of the yogurts under analysis. The smaller the flow distance, the higher the consistency of the yogurt (McCarthy and Seymour, 1993). The analyses with the Bostwick consistometer were carried out inside a refrigerator (VWR International, Mont-Royal, QC, Canada) at $4^{\circ} \mathrm{C}$.

Flow through a Posthumus funnel (Posthumus, 1954) with standard geometry (Kutter et al., 2011) was determined using $300 \mathrm{~g}$ of yogurt. The flow time for $280 \mathrm{~g}$ of yogurt was recorded as a function of mass using a balance (model P-2002, Pinnacle series; Denver Instrument, Mississauga, ON, Canada) connected to a data acquisition system. The yogurt flowed by gravity, and the flow time varied depending on the effect of the shear stresses exerted by different sections of the funnel (Monnet et al., 2008). Duplicates were performed for each sample of yogurt. The analyses with the Posthumus funnel were carried out inside a refrigerator at $4^{\circ} \mathrm{C}$ (VWR International).

\section{Determination of Contribution of Each Operation}

The contribution of each operation during the passage of the yogurt into the technical scale unit was determined by calculating the differences in properties (syneresis, viscosity, firmness, and consistency) from one operation to the next in relation to the total differences measured between the first and fifth sample collections. The values were reported as percentages. Equation [3] shows an example calculation of the percentage contribution of stirring in the yogurt vat to the development of a property value (PV). These calculations were performed for the 3 replicates of all stirred yogurt:

$$
\begin{aligned}
& \text { Contribution of stirring in the yogurt vat }(\%)= \\
& \frac{\mathrm{PV} \text { after stirring }-\mathrm{PV} \text { before stirring }}{\mathrm{PV} \text { at sample } 5-\mathrm{PV} \text { at sample } 1} \times 100 .
\end{aligned}
$$

\section{Experimental Designs and Statistical Analyses}

The 8 combinations of operating parameters $(2$ stirring durations, 2 smoothing temperatures, and 2 cooling systems) were randomized and repeated 3 times. A multivariate ANOVA (MANOVA) statistical design was used with the 2 stirring durations, 2 smoothing temperatures, and 2 cooling systems as the main factor and the 5 operations as the subplot factor. This design was used to determine the individual effects of the operations performed in each configuration as presented in Figure 1. A split-plot design was used with the 8 combinations of operating parameters as the main factor and the operations (stirring, pumping, smoothing, and cooling) as the subplot factor; however, the raw values were replaced by the percentage contributions. This design was used to determine the contribution of each operation to the total change in properties during the passage of the yogurt into the technical scale unit used in each configuration. Significant differences were tested at $P \leq 0.05$. The statistical analyses were carried out with the GLM (general linear model) procedure in SAS software (SAS Server Interface, version 2.5.14; SAS Institute Inc., Cary, NC).

\section{RESULTS}

\section{Composition of Yogurt Milk}

All yogurts had the same composition (fat: $0.17 \pm$ $0.03 \%$; TS: $14.0 \pm 0.1 \%$; true protein: $4.2 \pm 0.1 \%$; caseins: $3.10 \pm 0.02$; whey protein: $1.11 \pm 0.03$; and casein:whey protein ratio: $2.79 \pm 0.03$ ).

\section{Evolution of $\mathrm{pH}$ and Bacterial Populations}

After stirring in the yogurt vat, the $\mathrm{pH}$ of all yogurts changed from $4.70 \pm 0.01$ to $4.61 \pm 0.01$. After the smoothing, cooling, and packing operations, the $\mathrm{pH}$ of all yogurts decreased to $4.51 \pm 0.01$, and after $24 \mathrm{~h}$ of storage, the $\mathrm{pH}$ of all yogurts sampled decreased to 4.36 \pm 0.01 due to post-acidification by lactic acid bacteria (as described by Beal et al., 1999). Lactobacilli and streptococci populations were, respectively, $8.29 \pm 0.05$ and $8.47 \pm 0.02 \log \mathrm{cfu} / \mathrm{mL}$ in all yogurts.

\section{Changes in Syneresis During the Process}

Figure 2 presents the changes in syneresis of yogurt sampled after each individual operation according to configuration (Figure 2A: configuration 1; Figure 2B: configuration 2) used for the technical scale unit. Unexpectedly, a significant effect $(P \leq 0.05)$ of configuration was observed for yogurt taken before stirring and analyzed after $1 \mathrm{~d}$ (YV). However, syneresis values for the samples taken in $\mathrm{YV}$ were $28 \% \pm 1 \%$ for the first configuration and $32 \% \pm 1 \%$ for the second configuration. During the operations, a decrease in syneresis was observed for both configurations (Figure 2). No significant effect $(P>0.05)$ was observed for stirring duration (St5 or St10). For both configurations, a significant difference $(P \leq 0.05)$ was observed between PHX and THX after the pumping (PU and PU+PSM) operation (Figure 2). Syneresis was lower if the sequence of operations included PHX. However, if syneresis decreased 
a PHX $\mathbf{v T H X}$
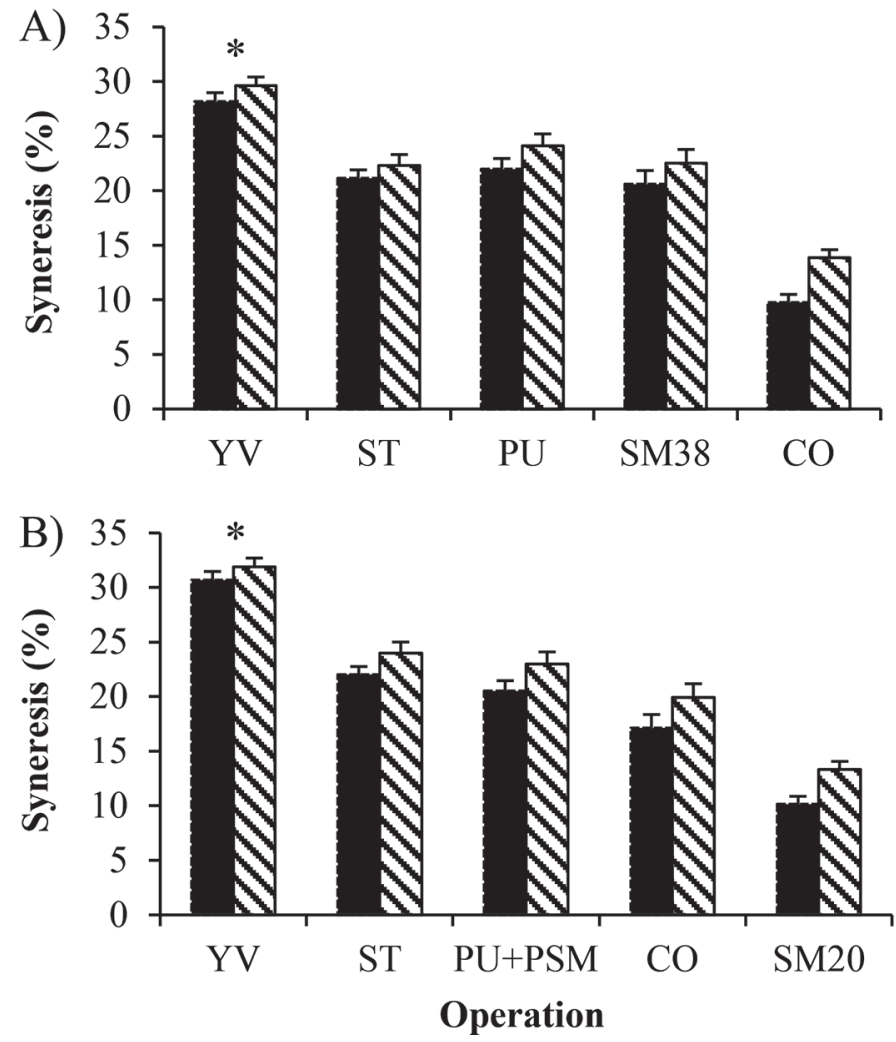

Figure 2. Syneresis values obtained for the yogurts stirred with (A) configuration 1, or (B) configuration 2 of the technical scale unit depending on the cooling system used: plate (PHX) or tubular (THX) heat exchanger. Operations were as follows: $\mathrm{YV}=$ before stirring in the yogurt vat; $\mathrm{ST}=$ after stirring; $\mathrm{PU}=$ after pumping; $\mathrm{PU}+\mathrm{PSM}=$ after pumping and pre-smoothing; SM38 = after smoothing at $38^{\circ} \mathrm{C}$; SM20 = after smoothing at $20^{\circ} \mathrm{C} ; \mathrm{CO}=$ after cooling with PHX or THX. Syneresis values for ST are the average of 5 and $10 \mathrm{~min}$ of stirring. The error bars represent the standard error of the means. Significant differences between configurations (panel A vs. B) are identified by an asterisk $(*)$.

after the stirring step, pumping did not change the syneresis value except in configuration 1 , where syneresis increased slightly after the pumping step (PU: Figure 2A). After the smoothing (SM38 or SM20) and cooling operations, yogurt syneresis decreased and syneresis values were similar in both configurations even if these operations were performed in a different order. At the end of the process, syneresis was lower in yogurts cooled with PHX (Figure 2AB).

When the contribution of each operation to the total change in syneresis was expressed as a percentage (Supplemental Figure S1; https://doi.org/10.3168/ jds.2018-14565), stirring operation contributed significantly to reduce syneresis in both configurations. The contribution of both cooling systems (PHX and THX) in syneresis was statistically similar. However, the contribution of cooling system to reduce syneresis was higher when smoothing was carried out at $38^{\circ} \mathrm{C}$ (configuration 1 ) than at $20^{\circ} \mathrm{C}$ (configuration 2$)$.

\section{Changes in Viscosity During the Process}

The changes in apparent viscosity of yogurts sampled after each operation and analyzed after $1 \mathrm{~d}$ are presented in Figure 3 according to the configuration used for the technical scale; that is, configuration 1 (Figure $3 \mathrm{~A})$ or 2 (Figure $3 \mathrm{~B})$. No difference $(P>0.05)$ was observed between yogurt samples taken before stirring in the yogurt vat. No significant effect $(P>0.05)$ of stirring duration (St5 or St10) or cooling system (PHX or THX) was observed (Figure 3). A significant effect $(P \leq 0.05)$ of the configuration was observed for yogurt samples taken after smoothing at $38^{\circ} \mathrm{C}$ (Figure $3 \mathrm{~A}$ ) and after the cooling operation of configuration 2 (Figure 3B). Apparent viscosity increased continuously with configuration 1 (Figure 3A) but decreased after cooling operations with configuration 2 (Figure 3B). Nevertheless, no significant difference in viscosity was observed between the yogurt samples taken at the end of the process.

The contribution of each operation to the total change in viscosity expressed as a percentage (Supplemental Figure S2; https://doi.org/10.3168/jds.2018-14565) shows that stirring operations in both configurations contributed similarly to increase viscosity, whereas PU (configuration 1) contributed significantly more to increase viscosity than PU+PSM (configuration 2). The contribution of both cooling systems (PHX and THX) to viscosity was statistically similar. Smoothing made a greater contribution to increase viscosity when it was performed at $20^{\circ} \mathrm{C}$ after cooling (configuration 2) than at $38^{\circ} \mathrm{C}$ before cooling (configuration 1 ).

\section{Changes in Firmness During the Process}

The firmness values of yogurt sample taken after each operation and analyzed after $1 \mathrm{~d}$ of storage are presented in Figure 4 according to the configuration used for the technical scale unit (Figure 4A: configuration 1 or Figure 4B: configuration 2). No difference $(P$ $>0.05)$ was observed between yogurt samples taken before stirring (YV). Stirring duration (St5 and St10) and pumping operations (PU and PU+PSM) did not have a significant effect on firmness $(P>0.05)$, but configuration was found to have a significant effect $(P$ $\leq 0.05$ ) for the last 2 operations performed. For both configurations, firmness decreased continuously after each operation except after the smoothing step (SM38 and SM20), which increased firmness. This increase in firmness was observed especially in configuration 1 
(Figure 4A) when SM38 was performed before cooling. In addition, a significant effect $(P \leq 0.05)$ of the type of cooling system (PHX or THX) was observed (Figure 4). At the end of the process, the firmness of yogurts was greater when THX was used and even higher when this system was used in configuration 1 .

The contribution of each operation to the total change in firmness expressed as a percentage (Supplemental Figure S3; https://doi.org/10.3168/jds.2018 -14565) indicated that stirring, pumping, and cooling operations in both configurations contributed significantly to decrease firmness, whereas a smoothing step, especially at $38^{\circ} \mathrm{C}$, contributed to increase the firmness. The contribution of PHX and THX cooling system in firmness was statistically similar.

\section{* PHX $\mathbf{Q T H X}$}
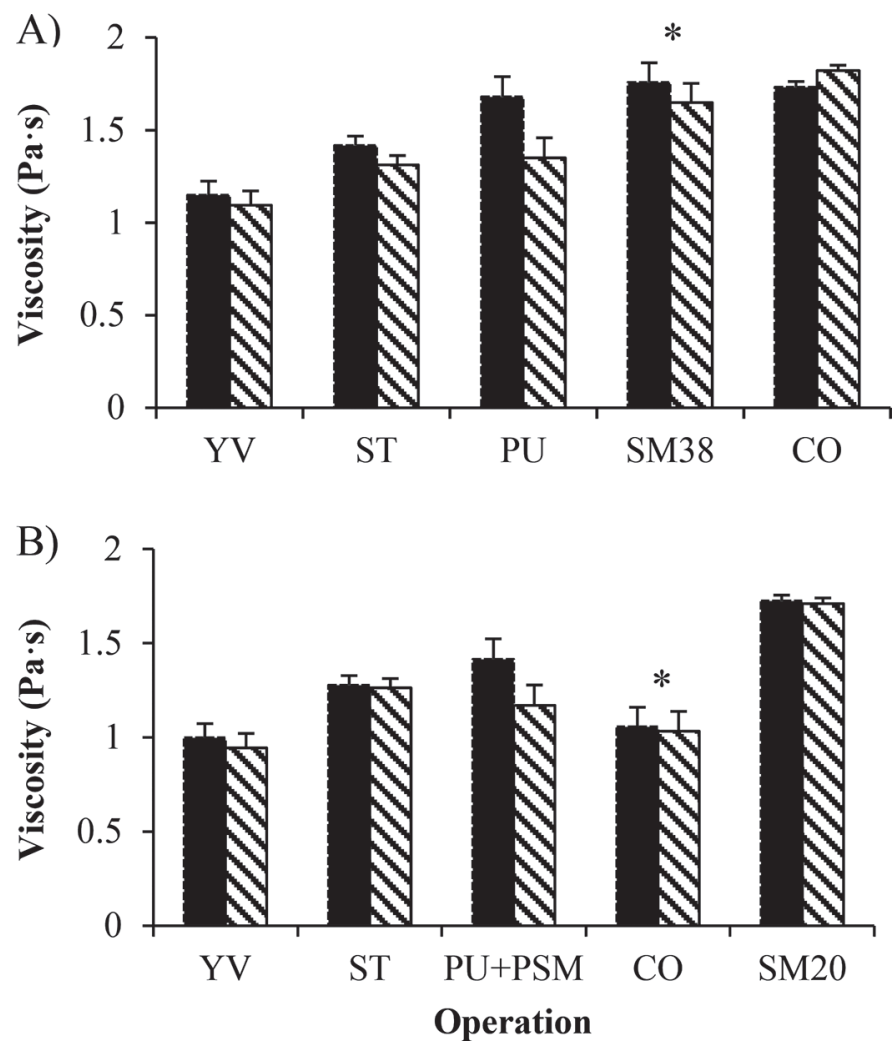

Figure 3. Viscosity values obtained for the yogurts stirred with (A) configuration 1, or (B) configuration 2 of the technical scale unit depending on the cooling system used: plate (PHX) or tubular (THX) heat exchanger. Operations were as follows: $\mathrm{YV}=$ before stirring in the yogurt vat; $\mathrm{ST}=$ after stirring; $\mathrm{PU}=$ after pumping; $\mathrm{PU}+\mathrm{PSM}=$ after pumping and pre-smoothing; SM38 = after smoothing at $38^{\circ} \mathrm{C}$; SM20 $=$ after smoothing at $20^{\circ} \mathrm{C}$; $\mathrm{CO}=$ after cooling with $\mathrm{PHX}$ or THX. Viscosity values for ST are the average of 5 and $10 \mathrm{~min}$ of stirring. The error bars represent the standard error of the means. Significant differences between configurations (panel A vs. B) are identified by an asterisk $(*)$.
PHX $\mathbf{T T H X}$
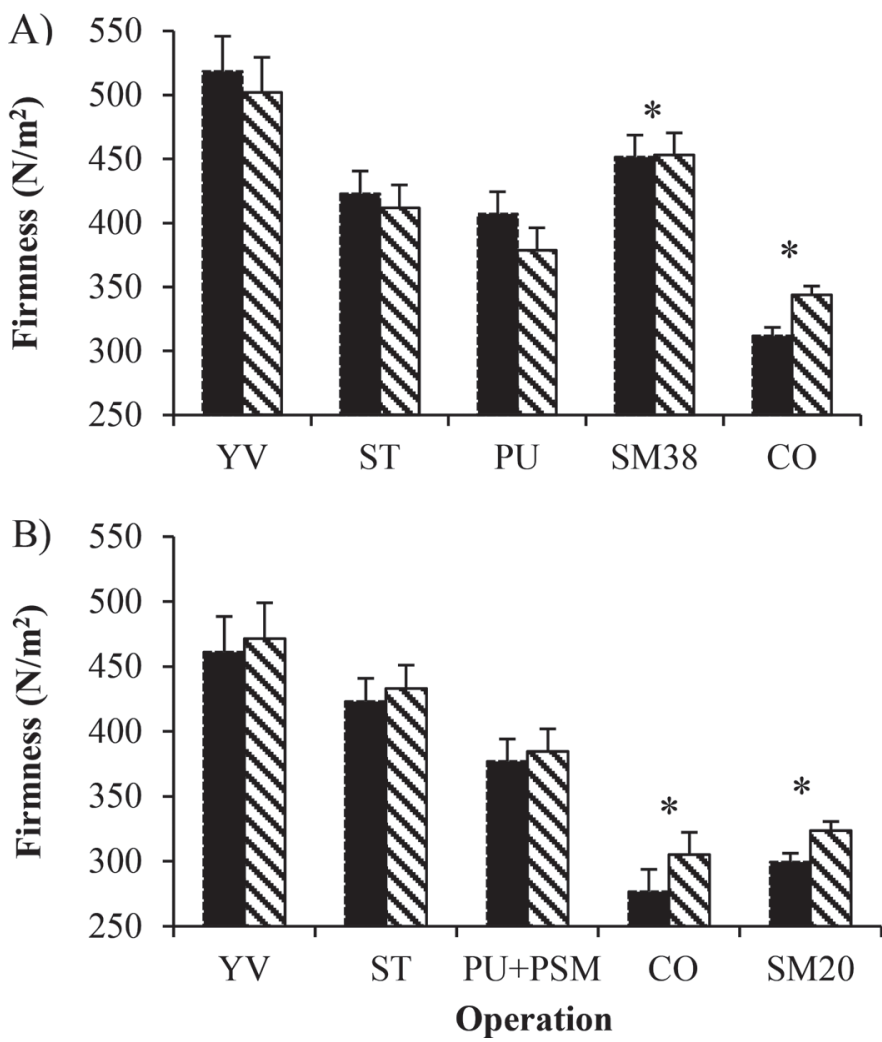

Figure 4. Firmness values obtained for the yogurts stirred with (A) configuration 1, or (B) configuration 2 of the technical scale unit depending on the cooling system used: plate (PHX) or tubular (THX) heat exchanger. Operations were as follows: $\mathrm{YV}=$ before stirring in the yogurt vat; $\mathrm{ST}=$ after stirring; $\mathrm{PU}=$ after pumping; $\mathrm{PU}+\mathrm{PSM}=$ after pumping and pre-smoothing; SM38 = after smoothing at $38^{\circ} \mathrm{C}$; SM20 $=$ after smoothing at $20^{\circ} \mathrm{C} ; \mathrm{CO}=$ after cooling with $\mathrm{PHX}$ or THX. Firmness values for ST are the average of 5 and $10 \mathrm{~min}$ of stirring. The error bars represent the standard error of the means. Significant differences between configurations (panel A vs. B) are identified by an asterisk $(*)$.

\section{Changes in Distance Traveled in the Bostwick Consistometer During the Process}

Figure 5 presents the changes in the distances traveled in the Bostwick consistometer for the yogurt samples collected after each operation for configuration 1 (Figure 5A) or 2 (Figure 5B) of the technical scale unit used and analyzed after $1 \mathrm{~d}$. No difference $(P$ $>0.05)$ was observed between yogurt samples taken before the stirring (YV). Stirring duration (St5 or St10) and pumping operations (PU and PU+PSM) did not significantly affect $(P>0.05)$ the distance measured with the Bostwick consistometer. However, a significant effect $(P \leq 0.05)$ of configuration was observed for the last 2 operations performed. The distance traveled by yogurts increased gradually during different operations in both configurations, indicating a decrease in con- 
sistency (Figure 5). For both configurations, cooling increased the distance traveled, especially when cooling was performed before the smoothing step (Figure 5B). A significant effect $(P \leq 0.05)$ of the cooling system (PHX or THX) was observed at the end of the process (Figure 5). In each configuration, the distance traveled was longer for yogurts cooled with PHX than THX and even greater when configuration 2 was used.

The contribution of each operation to the total change in the distances traveled in the Bostwick consistometer expressed as a percentage (Supplemental Figure S4; https://doi.org/10.3168/jds.2018-14565) indicated that, for both configurations, stirring and pumping operations contributed similarly to increase the distance traveled. The contribution of both cooling systems (PHX and THX) in distance traveled was statistically similar. The smoothing step decreased the distance traveled whereas the cooling step increased it. However, the contribution of smoothing and cooling steps was smaller when smoothing was performed at $38^{\circ} \mathrm{C}$ (configuration 1) than when smoothing was carried out at $20^{\circ} \mathrm{C}$ (configuration 2 ).

\section{DISCUSSION}

During processing of stirred yogurt, the gel is broken into particles of different sizes, which are dispersed in the whey (Zoon, 2003). Lucey (2004) observed that bonds between proteins are restored, allowing the gel network to build up quickly after potting. We expected that each unit operation would have a different effect, as discussed in the following section.

\section{Effect of Unit Operations on the Properties of Yogurt}

Stirring. After fermentation, the yogurt gel was stirred for 5 and $10 \mathrm{~min}$ at $30 \mathrm{rpm}$. No difference was observed between stirred yogurts. Little information is available in the literature on the effect of different stirring durations on the properties of stirred yogurt. Chandan and O'Rell (2006) explained that stirring should not be too intense or too long but no details about stirring speed or duration were described. The stirring duration and intensity used in this study may not have been high enough to observe significant differences.

Pumping. The pumping step used with or without the pre-smoothing nozzle had very little effect on syneresis, firmness, or consistency of yogurts sampled after this step and analyzed after $1 \mathrm{~d}$ of storage. The use of a low-rotation positive pump producing low pressure at the pump outlet could explain why the effect on gel properties was small. Few results are reported in the literature on the effect of the pumping operation on vis-
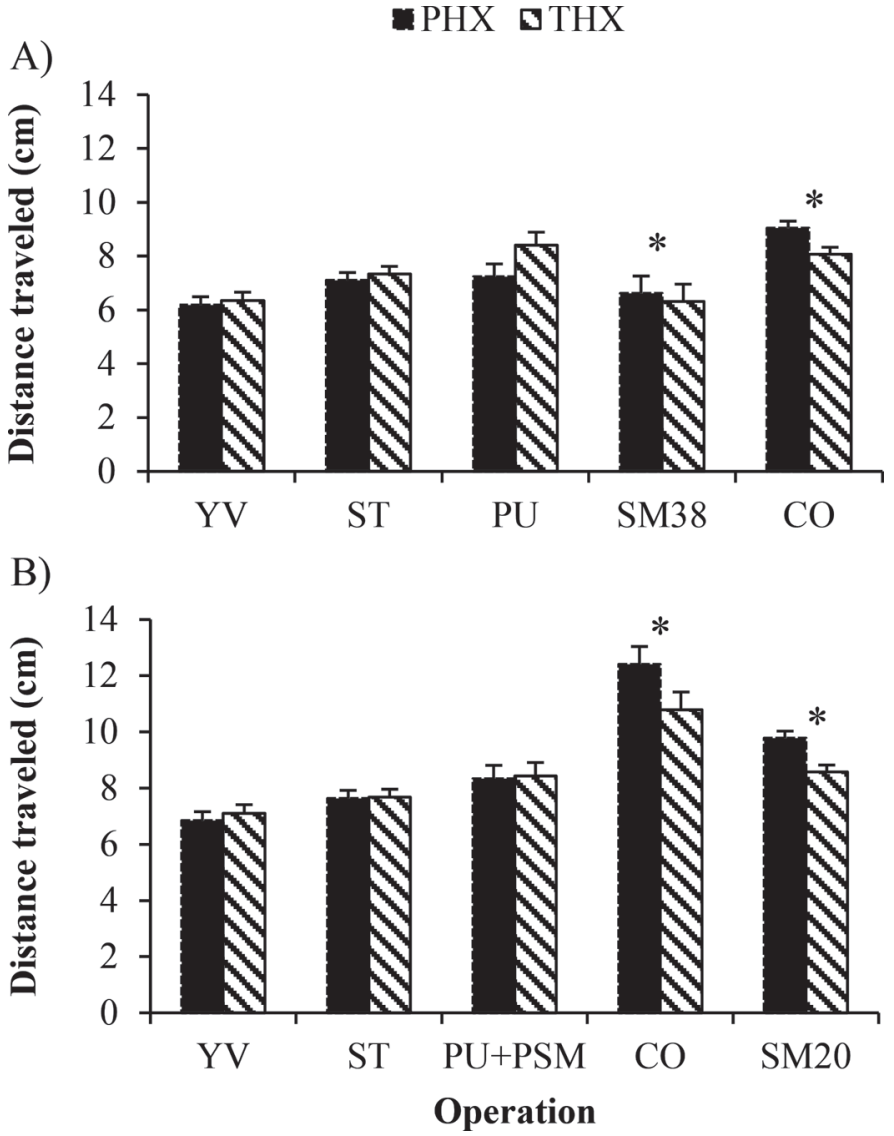

Figure 5. Values for distance traveled in the Bostwick consistometer obtained for the yogurts stirred with (A) configuration 1 , or (B) configuration 2 of the technical scale unit depending on the cooling system used: plate (PHX) or tubular (THX) heat exchanger. Operations were as follows: $\mathrm{YV}=$ before stirring in the yogurt vat; $\mathrm{ST}=$ after stirring; $\mathrm{PU}=$ after pumping; $\mathrm{PU}+\mathrm{PSM}=$ after pumping and pre-smoothing; SM38 = after smoothing at $38^{\circ} \mathrm{C}$; SM20 = after smoothing at $20^{\circ} \mathrm{C}$; $\mathrm{CO}=$ after cooling with PHX or THX. Values for distance traveled for ST are the average of 5 and $10 \mathrm{~min}$ of stirring. The error bars represent the standard error of the means. Significant differences between configurations (panel A vs. B) are identified by an asterisk $(*)$.

cosity. Senge and Blochwitz (2009) obtained a decrease in viscosity after the pumping operation. However, they used a high-rotation pump creating a higher pressure (5.0 bar or $500 \mathrm{kPa}$ ) and consequently higher mechanical stress than the one used in this study ( 0.2 bars or $20 \mathrm{kPa}$ ), which may explain the lower viscosity (Yoon and McCarthy, 2002; Maingonnat et al., 2005; Jaros et al., 2007; Abu-Jdayil et al., 2013).

The type of heat exchanger (PHX or THX) affected syneresis, with lower values for PHX. This could be explained by higher pressure values after the pump when PHX was used compared with the THX system (27.6 and $13.8 \mathrm{kPa}$ ) causing higher mechanical stress (Senge and Blochwitz, 2009). This would increase the pressure drop in the system, which creates a loss of en- 
ergy due to the higher friction of the fluid between the plates (O'Donnell and Butler, 2002). This could affect the protein network, making it more homogeneous and improving whey retention (Puvanenthiran et al., 2002).

Smoothing. The smoothing step creates a high mechanical stress that translates into a loss of gel structure and modification of the rheological properties of yogurts (Rasmussen et al., 2007; Zhang et al., 2016). The use of a filter nozzle reduces the size of gel particles and increases their aggregation level after packaging (Rasmussen et al., 2007; Mokoonlall et al., 2016). Gel particle aggregation results in a compact, homogeneous, and potentially more resistant network to mechanical stress (Puvanenthiran et al., 2002; Aichinger et al., 2003; Amatayakul et al., 2006). This is consistent with the increase in viscosity, firmness and consistency as well as the decrease of syneresis observed for both smoothing temperatures (SM38 or SM20) in this study.

Cooling. This step aims to reduce starter postacidification and improve yogurt textural properties (Lucey, 2004; Tamine and Robinson, 1999). Syneresis, consistency, and firmness were lower for yogurt cooled with the PHX. However, the type of cooling system (PHX or THX) used did not affect the viscosity values. It should be noted that the rebodying occurring during the first hours of storage could have masked the differences between yogurts cooled with PHX and THX systems (Renan et al., 2008). The PHX system cooled the yogurt quickly and uniformly but induced a greater mechanical stress than the THX system (approximately 2-fold greater; Afonso et al., 2003; Fernandes et al., 2005; Maingonnat et al., 2005; Senge and Blochwitz, 2009). Mokoonlall et al. (2016) explained that the higher mechanical stress is caused by a higher flow rate and larger angles between plates. The higher mechanical stress could be associated with smaller gel particle. Aichinger et al. (2003) and Lorenzen et al. (2002) observed that the presence of smaller pores in the yogurt network would reduce whey mobility and syneresis as observed for yogurts cooled with the plate system.

\section{Contribution of Individual and Sequential Operations}

Comparison of properties of yogurt samples taken immediately after each operation (but analyzed after 1 $\mathrm{d}$ of storage) with the final yogurt allowed estimation of not only the contribution of individual operations but also the effect of sequential operations. When using the technical scale unit, the effect of each operation was dependent on the previous processing steps.

The stirring step in the yogurt vat (St5 or St10) made a major contribution mainly to the water retention properties of the final product followed by an effect of configuration. As mentioned previously, unit operations contributing to a homogeneous network contribute to improve water retention (Puvanenthiran et al., 2002). Of note, syneresis at the end of the process was not significantly affected by configuration. In general, the pumping step (PU or PU+PSM) made the smallest contribution to the rheological and physical properties of the yogurts. The smoothing and cooling steps each made important contributions, which depend importantly on the sequence of operations (configuration 1 or 2$)$. Smoothing at a lower temperature $\left(20^{\circ} \mathrm{C}\right.$; configuration 2) had a greater effect on viscosity, consistency, and syneresis values than did smoothing at $38^{\circ} \mathrm{C}$ (configuration 1). These results are in agreement with the semiquantitative analysis reported in the review by Mokoonlall et al. (2016), showing that mechanical treatment occurring during yogurt processing affected viscosity according to treatment intensity. Tamine and Robinson (2007) explained that smoothing the curd near fermentation temperature requires lower pressure than smoothing a cooled gel. Consequently, the difference in pressure may result in different particle sizes and gel properties (Cayot et al., 2003; Rasmussen et al., 2007; Mokoonlall et al., 2016). Despite the different contribution of smoothing and cooling steps in each configuration, the final yogurts had similar syneresis and viscosity but different firmness and consistency, showing the complexity at the interplay between factors optimizing gel properties and the effect of processing. Our experimental design did not allow us to gain knowledge on the rebodying process, and differences between configurations may have been hidden because all measurements were taken $1 \mathrm{~d}$ after manufacture. In this study, we did not evaluate milk standardization, which may also influence the effect of individual and sequential unit operations on yogurt properties. Yogurt making relies on an equilibrium between factors involved in gel formation (e.g., milk composition, starters) and the processing steps to reach optimal or desired properties to meet consumers' preferences.

\section{CONCLUSIONS}

This investigation of the individual effects of stirring in the yogurt vat, smoothing, and cooling demonstrated that the sequence of operations (smoothing before or after cooling) modifies the rheological properties (viscosity, firmness, and consistency) of nonfat yogurt processed in a technical scale unit. In general, syneresis, firmness, and consistency decreased and viscosity increased after each of the operations performed in the unit. Compared with stirring and pumping, smoothing and cooling had the highest individual contribution 
on physical and rheological properties of the yogurts. Gel properties are known to evolve during storage and should be investigated in a future study. The use of a technical scale unit demonstrated that the rheological and physical properties of nonfat stirred yogurt depend on the sequence and combination of the stirring, smoothing, and cooling parameters. The technical scale unit used in this study could be adapted with different types of pumping and smoothing devices. Additional work is planned to analyze stirred yogurt microstructure (size and morphology of gel particles) to better understand the relationship between gel structure and functional properties.

\section{ACKNOWLEDGMENTS}

This study was jointly funded by the research programs of the Fonds de Recherche du Québec et Nature et Technologies (Quebec, QC, Canada), Novalait Inc. (Quebec, QC, Canada), and the Ministère de l'Agriculture, des Pêcheries et de l'Alimentation du Québec (MAPAQ; Quebec, QC, Canada). The authors thank Gaétan Bélanger, Louis-Philippe Desmarchais, and Stefan Grabowski (St-Hyacinthe Research and Development Centre, St-Hyacinthe, QC, Canada) for their technical assistance in the production of yogurts at the technical scale, and Annie Caron and Sophie Turcot (St-Hyacinthe Research and Development Centre, StHyacinthe, QC, Canada) for their technical assistance with the analyses.

\section{REFERENCES}

Abu-Jdayil, B., M. S. Nasser, and M. Ghannam. 2013. Structure breakdown of stirred yoghurt in a circular pipe as affected by casein and fat content. Food Sci. Technol. Res. 19:277-286.

Afonso, I. M., L. Hes, J. M. Maia, and L. F. Melo. 2003. Heat transfer and rheology of stirred yoghurt during cooling in plate heat exchangers. J. Food Eng. 57:179-187.

Aichinger, P.-A., M. Michel, C. Servais, M.-L. Dillmann, M. Rouvet, N. D'Amico, R. Zink, H. Klostermeyer, and D. S. Horne. 2003. Fermentation of a skim milk concentrate with Streptococcus thermophilus and chymosin: Structure, viscoelasticity and syneresis of gels. Colloids Surf. B Biointerfaces 31:243-255.

Amatayakul, T., A. L. Halmos, F. Sherkat, and N. P. Shah. 2006. Physical characteristics of yoghurts made using exopolysaccharideproducing starter cultures and varying casein to whey protein ratios. Int. Dairy J. 16:40-51.

AOAC. 1990. Official Methods of Analysis. 15th ed. Association of Official Agricultural Chemists, Arlington, VA.

AOAC International. 2000. Dairy products. 17th ed. Pages 69-82 in Official Methods of Analysis of AOAC International. Vol. 2. W. Horwitz, ed. AOAC International, Gaithersburg, MD.

Arshad, M., M. Paulsson, and P. Dejmek. 1993. Rheology of buildup, breakdown, and rebodying of acid casein gels. J. Dairy Sci. 76:3310-3316.

ASTM. 2013. Standard F1080-93: Standard test method for determining the consistency of viscous liquids using a consistometer. ASTM International, West Conshohocken, PA.
Beal, C., J. Skokanova, E. Latrille, N. Martin, and G. Corrieu. 1999. Combined effects of culture conditions and storage time on acidification and viscosity of stirred yogurt. J. Dairy Sci. 82:673-681.

Canadian Dairy Information Centre. 2018. Consumption of dairy products (annual). http://www.dairyinfo.gc.ca/index_e.php?s1= dff-fcil\&s2 $=$ cons\&s3= conscdn\&s4= dpcons\&page $=$ consdppl.

Cayot, P., J.-F. Fairise, B. Colas, D. Lorient, and G. Brulé. 2003. Improvement of rheological properties of firm acid gels by skim milk heating is conserved after stirring. J. Dairy Res. 70:423-431.

Cayot, P., F. Schenker, G. Houzé, C. Sulmont-Rossé, and B. Colas. 2008. Creaminess in relation to consistency and particle size in stirred fat-free yogurt. Int. Dairy J. 18:303-311.

Chandan, R. C., and K. R. O'Rell. 2006. Manufacture of various types of yogurt. Pages 211-236 in Manufacturing Yogurt and Fermented Milks. R. C. Chandan, ed. Blackwell Publishing, Ames, IA.

Everett, D. W., and R. E. McLeod. 2005. Interactions of polysaccharide stabilisers with casein aggregates in stirred skim-milk yoghurt. Int. Dairy J. 15:1175-1183.

Fernandes, C. S., R. Dias, J. M. Nóbrega, I. M. Afonso, L. F. Melo, and J. M. Maia. 2005. Simulation of stirred yoghurt processing in plate heat exchangers. J. Food Eng. 69:281-290.

Gentès, M.-C., D. St-Gelais, and S. L. Turgeon. 2013. Exopolysaccharide-milk protein interactions in a dairy model system simulating yoghurt conditions. Dairy Sci. Technol. 93:255-271.

Hess, S. J., R. F. Roberts, and G. R. Ziegler. 1997. Rheological properties of nonfat yogurt stabilized using Lactobacillus delbrueckii ssp. bulgaricus producing exopolysaccharide or using commercial stabilizer systems. J. Dairy Sci. 80:252-263.

ISO-IDF. 2003. ISO 7889/IDF 117: Yogurt-Enumeration of characteristic microorganisms-Colony-count technique at $37^{\circ} \mathrm{C}$. International Organization for Standardization, Geneva, Switzerland, and International Dairy Federation, Brussels, Belgium.

Jaros, D., C. Heidig, and H. Rohm. 2007. Enzymatic modification through microbial transglutaminase enhances the viscosity of stirred yogurt. J. Texture Stud. 38:179-198.

Kutter, A., J. P. Singh, C. Rauh, and A. Delgado. 2011. Improvement of the prediction of mouthfeel attributes of liquid foods by a posthumus funnel. J. Texture Stud. 42:217-227.

Lorenzen, P. C., H. Neve, A. Mautner, and E. Schlimme. 2002. Effect of enzymatic cross-linking of milk proteins on functional properties of set-style yoghurt. Int. J. Dairy Technol. 55:152-157.

Lucey, J. A. 2004. Cultured dairy products: An overview of their gelation and texture properties. Int. J. Dairy Technol. 57:77-84.

Maingonnat, J. F., L. Muller, and J. C. Leuliet. 2005. Modelling the build-up of a thixotropic fluid under viscosimetric and mixing conditions. J. Food Eng. 71:265-272.

McCarthy, K. L., and M. J. McCarthy. 2009. Relationship between inline viscosity and Bostwick measurement during ketchup production. J. Food Sci. 74:E291-E297.

McCarthy, K. L., and J. D. Seymour. 1993. A fundamental approach for the relationship between the Bostwick measurement and Newtonian fluid viscosity. J. Texture Stud. 24:1-10.

Mokoonlall, A., S. Nöbel, and J. Hinrichs. 2016. Post-processing of fermented milk to stirred products: Reviewing the effects on gel structure. Trends Food Sci. Technol. 54:26-36.

Monnet, C., E. Latrille, C. Béal, and G. Corrieu. 2008. Croissance et propriétés fonctionnelles des bactéries lactiques. Chapter 4. Pages 512-594 in Tec et Doc Editions. Bactéries Lactiques. De la génétique aux ferments. Lavoisier, Cachan, France.

O'Donnell, H. J., and F. Butler. 2002. Time-dependent viscosity of stirred yogurt. Part II: Tube flow. J. Food Eng. 51:255-261.

Posthumus, G. 1954. Meten van de viscositeit. Een toestelletje voor het bepalen van de viscositeit van enkele consumtiemelkproducten. Officieel Orgaan van de Koninklijke Nederlandse Zuivelbond. $4: 55-56$.

Puvanenthiran, A., R. P. W. Williams, and M. A. Augustin. 2002. Structure and visco-elastic properties of set yoghurt with altered casein to whey protein ratios. Int. Dairy J. 12:383-391.

Rasmussen, M. A., T. Janhøj, and R. Ipsen. 2007. Effect of fat, protein and shear on graininess, viscosity and syneresis in low-fat stirred yoghurt. Milchwissenschaft 62:54-58. 
Renan, M., F. Guyomarc'h, V. Arnoult-Delest, D. Pâquet, G. Brulé, and M.-H. Famelart. 2008. The rebodying of stirred yoghurt: Interactions between proteins. J. Dairy Res. 75:450-456.

Renan, M., F. Guyomarc'h, V. Arnoult-Delest, D. Pâquet, G. Brulé, and M.-H. Famelart. 2009. Rheological properties of stirred yoghurt as affected by gel $\mathrm{pH}$ on stirring, storage temperature and $\mathrm{pH}$ changes after stirring. Int. Dairy J. 19:142-148.

Sanchez, C., J.-L. Beauregard, M.-H. Chassagne, A. Duquenoy, and J. Hardy. 1994. Rheological and textural behaviour of double cream cheese. Part II: Effect of curd cooling rate. J. Food Eng. 23:595608.

Senge, B., and R. Blochwitz. 2009. Einfluss der Prozesstechnik auf die Strukturstabilität pastöser Milchprodukte. Teil 3. Deutsche Milchwirtschaft (Hildesheim) 60:553-557. [In German]

Sodini, I., F. Remeuf, S. Haddad, and G. Corrieu. 2004. The relative effect of milk base, starter, and process on yogurt texture: A review. Crit. Rev. Food Sci. Nutr. 44:113-137.

Tamine, A. Y., and R. K. Robinson. 1999. Yoghurt Science and Technology. 2nd ed. CRC Press, Boca Raton, FL, and Woodhead Publishing, Cambridge, UK.
Tamine, A. Y., and R. K. Robinson. 2007. Yoghurt Science and Technology. 3rd ed. CRC Press, Boca Raton, FL, and Woodhead Publishing, Cambridge, UK.

Teles, C. D., and S. H. Flôres. 2007. The influence of additives on the rheological and sensory properties of nonfat yogurt. Int. J. Dairy Technol. 60:270-276.

Trachoo, N. 2002. Yogurt: The fermented milk. Songklanakarin J. Sci. Technol. 24:727-737.

Yoon, W. B., and K. L. McCarthy. 2002. Rheology of yogurt during pipe flow as characterized by magnetic resonance imaging. J. Texture Stud. 33:431-444.

Zhang, L., D. M. Folkenberg, J. M. Amigo, and R. Ipsen. 2016. Effect of exopolysaccharide-producing starter cultures and post-fermentation mechanical treatment on textural properties and microstructure of low fat yoghurt. Int. Dairy J. 53:10-19.

Zoon, P. 2003. Viscosity, smoothness and stability of yogurt as affected by structure and EPS functionality. Pages 280-289 in Fermented Milk. Special issue 0301. International Dairy Federation, Brussels, Belgium. 